\title{
EXPOSURE TOWARDS HAND, FOOT AND MOUTH DISEASE (HFMD) AWARENESS AND SOURCES OF INFORMATION AMONG CARETAKERS
}

\author{
${ }^{1}$ Dr. Yuzana Binti Mohd Yusop \\ ${ }^{I}$ Senior Lecturer Faculty of Medicine, Universiti Sultan Zainal Abidin (UniSZA) Malaysia \\ ${ }^{2}$ Nurul Asyikin Binti Ahmad \\ ${ }^{2}$ Researcher Faculty of Medicine, Universiti Sultan Zainal Abidin (UniSZA) Malaysia \\ ${ }^{3}$ Zakirah Binti Ahmad Nawi \\ ${ }^{3}$ Researcher Faculty of Medicine, Universiti Sultan Zainal Abidin (UniSZA) Malaysia
}

DOI: https://doi.org/10.36713/epra1599

\begin{abstract}
Using a sample of kindergarten caretakers, this study shows that knowledge about Hand food and mouth disease (HFMD) is considered to be moderate (62.0\%). Questionnaires were attained from 197 caretakers from a range of kindergarten in Kuala Nerus district, via universal sampling. The study shows that, within the sample of Kuala Nerus caretakers, insufficient HFMD knowledge does not diverge between educational background and source of health information. The research also indicates that those with experience are more conversant workers. Electronic and social media are the most selected channel by the caretakers for obtaining knowledge.

KEYWORDS:HFMD, Caretakers, Kindergarten, Source of Information.
\end{abstract}

\section{INTRODUCTION}

Hand Food and Mouth Disease (HFMD) is a common viral infection caused by a range of enteroviruses such as polioviruses, coxsackievirus and echoviruses (WHO, 2012). Over the past decade, numerous outbreaks of HFMD have been reported

from countries in Asia including China, Japan, Taiwan, Malaysia, Vietnam, and Singapore (WHO, 2011). The disease is causing an increased risk to public health worldwide (WHO, 2011). In Malaysia the prevalence, incidence, aetiology and disease burden of HFMD was principally unknown before
May 1997. Around Asia, recurring epidemics of HFMD linked with severe neurological disease are becoming a major public health concern. Even through HFMD generally affects young children, especially those five years and below, the natural host of HFMD initiating enteroviruses is humans. Therefore, it is possible that human movement is crucial to the transmission and spread of HFMD for both the worldwide and local scales. There has been abundant research on the HFMD and related risk factors. In Malaysia, most research about HFMD has been directed towards laboratory-based research to

| Volume: 4 | Issue: 11 | November| 2019 Journal DOI: https://doi.org/10.36713/epra2016 |www.eprajournals.com |73 | 
differentiate the viruses, risk factors and preventive practices towards the disease. Therefore, the present study is carried out due to the deficiency of studies on the HFMD knowledge among children's caretakers in Malaysia. Most studies of this type have focused on pre-school teachers and parents.

\section{METHODS}

In this study, caretakers are defined as people who are involved in handling and taking care of young children. The term 'caretaker' refers to those who have direct contact with children in pre-schools and kindergartens in Kuala Nerus district, including teachers and their assistants. For this paper, researchers focused on the understanding and source of information about HFMD among caretakers.

To assess HFMD knowledge, in this study researchers used a five-item knowledge survey modified from Othman et al. (2012). Caretakers were asked to answer from "strongly disagree" to "strongly agree" to knowledge-related items. A knowledge score ranging from 1 to 5 was derived from the sum of correct responses. Nine questions addressed this issue as listed in Table 2. Cronbach's alpha was computed to measure the internal consistency of these nine knowledge items. The items have good internal consistency, with Cronbach's alpha coefficients of .77. The sample size for this study is based on objective number two from the main study, which yielded the highest number $(n=412)$. The estimated proportion of people with a high level of knowledge regarding HFMD among children's caretakers is $3.7 \%$ and desired precision is $1.85 \%$ (0.0185). However, for this article's purposes, the data collection for this research was conducted only for the first phase from the main study. About 245 questionnaires were distributed to schools in the location using universal sampling. The overall response rate with a fully completed survey questionnaire was $80.4 \%(\mathrm{n}=197)$.
To evaluate the source of information, researchers tend to explore which media is most accessible for caretakers in getting knowledge about HFMD. The researcher also attempted to determine which sourced of information would be favourable to get information about the disease because they are working in different schools in the district. The researchers listed five given answers on how they get the information about HFMD. The options are newspapers (printed), television (electronic media), internet (social media) and hospitals. An additional column was also provided so that respondents could write in any other sources they use. Participants were allowed to provide more than one solution.

\section{RESULTS \\ Demographic}

All caretakers that working in the kindergartens were female $(n=197)$. The mean age of the participants was 35.8 years $(\mathrm{SD}=9.53)$. The youngest was 19 years old, whereas the most senior was 59 years old. The socio-demographics are shown in Table 1. Most of the participants were married at $72.6 \%(\mathrm{n}=143)$. There were 51 single caretakers $(25.9 \%)$ with $3(1.5 \%)$ widows and divorcees. The majority of caretakers went to an institution of higher learning at $50.8 \%(n=100)$. If we break down the items, we can see that the degree level monopolizes this field of profession. Only one of the caretakers had completed a master's degree. About 73 (37.1\%) had completed their secondary school exams and approximately $24(12.2 \%)$ were lower than the rest. A majority of the caretakers have been working in this field quite some time, with those with more than 13 years' experience were 68 (34.5\%). However, 46 (23.4\%) newcomer caretakers had been working less than 3 years. The researchers categorized them as mediocre in the range of $4-6$ years $(18.3 \%), 7-9$ years $(11.7 \%)$ and $10-12$ years $(22.2 \%)$ years. The amounts are quite consistent for each group. 
Table 1: Demographic background of children's caretakerss

\begin{tabular}{lll}
\hline Demographic & Frequency & Percent \\
\hline Gender & & \\
Female & 197 & 100.0 \\
\hline Age & & \\
& & 34.5 \\
30 years and less & 68 & 35.5 \\
40 years and less & 70 & 21.3 \\
50 years and less & 42 & 8.6
\end{tabular}

\begin{tabular}{lll}
\hline Marital status & & \\
Single & 51 & 25.9 \\
Married & 143 & 72.6 \\
Widow/Divorcee & 3 & 1.5 \\
\hline Level of education & & \\
High School & 100 & 50.8 \\
Institute of higher & 73 & 37.1 \\
learning & 24 & 12.2 \\
Lower than above & & \\
mention & & \\
\hline
\end{tabular}

\section{Length of service}

$\begin{array}{lll}0-3 \text { years } & 46 & 23.4 \\ 4-6 \text { years } & 36 & 18.3 \\ 7-9 \text { years } & 23 & 11.7 \\ \text { 10-12 years } & 24 & 22.2 \\ \text { Above } 13 \text { years } & 68 & 34.5\end{array}$

\section{HFMD knowledge among caretakers}

For this study, the researchers used a five-item knowledge survey modified from Othman et al. (2012). The study result showed that the first and leading question is a general question to identify, whether the caretakers knew that children at the age of one to five easier to get infected. Researcher would expect majority of them have the capacity of knowledge upon this question. Unfortunately, almost $90 \% \quad(\mathrm{n}=178)$ did not know about it. This is considered the basic information about the infection. Twelve of them were uncertain about this information and only seven of the caretakers choose to agree with the statement. They supposed to know
35.5

21.3

8.6 
simpler, and caretakers should know that HFMD commonly occurs in kindergartens. Moderately, 43 $(21.8 \%)$ of caretakers agreed with this statement. However, nearly half $(66.0 \%)$ of them answered unfitting. For the fifth item, the researchers unexpectedly found that only $12(6.1 \%)$ of caretakers familiar were with close contact issue. A majority of the caretakers $(87.3 \%)$ have selected disagreement with the statement. The best alarming part was only one person totally confident about the direct contact transmission.

The researchers bring up the issue of vaccine that available against the viruses cause HFMD. The percentage of knowing, not knowing and uncertain category is about equal percentages. Practically, 60 (30.5\%) caretakers have knowledge of this issue. Yet, $77(39.1 \%)$ of them lack education about the nonexistence of HFMD vaccine. And at the same time the amount of caretakers unclear about the vaccination issue was $30.5 \%$. It is an excellent initiative to take to establish the habit of washing hands among children. The outcome of the given answer was disappointed. Only six (3.0\%) of caretakers would support the habit of hand washing and none of them select strongly agree with this question. To the researchers' surprise, 175 (88.9\%) of participants disapproved of this behaviour. For the eighth statement, researchers desired to know whether the caretakers could identify the symptoms of HFMD such as fever and blisters. The majority of the caretakers were ignorant about the symptoms. $182(91.6 \%)$ did not agree with the statement given and $11(5.6 \%)$ were uncertain about it too. Only four $(2.0 \%)$ had knowledge of the symptoms and at the same time none of them selected strongly agree with the statement. Generally, children's toys have been identified as one of the causes for the spread of the HFMD. For this closing question for knowledge part, once again the majority of the care takers' $89.9 \%$ $(\mathrm{n}=177)$ preferred an inappropriate answer. Not more than six $(3.0 \%)$ chosen the accurate answer, while 16 $(7.1 \%)$ were undecided about the statement.
Through the use of the Likert scale, participants were asked to rate their knowledge. The mean and standard deviation scores for the combination of the nine items were computed. The following are the results of the analysis: $\mathrm{N}=197$, $\mathrm{M}=23.96, \mathrm{SD}=4.81$. By looking at the mean, it appears that most participants scored moderately for the knowledge part for this study concerning HFMD, as the total score for the nine items had a potential range of 9 to 45 . The total score for the knowledge was 45 . The results show that 13 of the participants scored full marks. Those who scored higher mark were diploma holder and have been in the field for more than 13 years. The experience that they gain makes them scored with the higher range of mark for this part. The lowers score was 20 and she is the youngest (19 years old) at the same time have been working for less than 3 years.

Variety scored had been found according to range of ages; 20's, 30's, 40's and 50's. A majority of these groups were married. Seven respondents scored less than 30 marks and the majority of the caretakers scored less than 40 marks. Quite a number $(\mathrm{n}=55)$ managed to score between 40 to 45 . According the score finding, almost $62 \%(\mathrm{n}=122)$ of caretakers managed to get an average score ranging from 30 to 40 . 
Table 2: HFMD knowledge among caretakers

\begin{tabular}{|c|c|c|c|c|c|}
\hline Knowledge statements & $\begin{array}{l}\text { Strongly } \\
\text { Disagree }\end{array}$ & Disagree & Unsure & Agree & $\begin{array}{l}\text { Strongly } \\
\text { Agree }\end{array}$ \\
\hline $\begin{array}{l}\text { HFMD often happens to children from age of 1-5 years } \\
\text { old. }\end{array}$ & $\begin{array}{c}45.2 \% \\
(89)\end{array}$ & $\begin{array}{l}45.2 \% \\
(89)\end{array}$ & $\begin{array}{l}6.1 \% \\
(12) \\
\end{array}$ & $\begin{array}{c}3.6 \% \\
(7)\end{array}$ & $\begin{array}{l}0 \% \\
(0)\end{array}$ \\
\hline HFMD's disease is a type of infectious disease. & $\begin{array}{c}67.0 \% \\
(132)\end{array}$ & $\begin{array}{c}29.4 \% \\
(58)\end{array}$ & $\begin{array}{c}1.5 \% \\
(3)\end{array}$ & $\begin{array}{c}1.0 \% \\
(2)\end{array}$ & $\begin{array}{c}1.0 \% \\
(2)\end{array}$ \\
\hline HFMD can cause death. & $\begin{array}{c}43.7 \% \\
(86)\end{array}$ & $\begin{array}{c}32.0 \% \\
(63)\end{array}$ & $\begin{array}{c}19.8 \% \\
(39)\end{array}$ & $\begin{array}{c}1.5 \% \\
(3)\end{array}$ & $\begin{array}{c}3.0 \% \\
(6)\end{array}$ \\
\hline $\begin{array}{l}\text { The HFMD outbreak usually occurs in child care } \\
\text { centres' \& kindergartens.. }\end{array}$ & $\begin{array}{c}38.6 \% \\
(76)\end{array}$ & $\begin{array}{c}27.4 \% \\
(54)\end{array}$ & $\begin{array}{c}12.2 \% \\
(24)\end{array}$ & $\begin{array}{c}15.2 \% \\
(30)\end{array}$ & $\begin{array}{l}6.6 \% \\
(13) \\
\end{array}$ \\
\hline $\begin{array}{l}\text { HFMD spread through human contact touch from } \\
\text { infected person. }\end{array}$ & $\begin{array}{l}45.7 \% \\
(90)\end{array}$ & $\begin{array}{c}41.6 \% \\
(82)\end{array}$ & $\begin{array}{c}6.6 \% \\
(13)\end{array}$ & $\begin{array}{l}5.6 \% \\
(11)\end{array}$ & $\begin{array}{c}0.5 \% \\
(1)\end{array}$ \\
\hline $\begin{array}{l}\text { There are no vaccines that can prevent the infection of } \\
\text { HFMD. }\end{array}$ & $\begin{array}{c}13.2 \% \\
(26)\end{array}$ & $\begin{array}{c}25.9 \% \\
(51)\end{array}$ & $\begin{array}{c}30.5 \% \\
(60)\end{array}$ & $\begin{array}{c}21.3 \% \\
(42)\end{array}$ & $\begin{array}{l}9.1 \% \\
(18)\end{array}$ \\
\hline HFMD can be preventing by washing hand properly. & $\begin{array}{c}44.7 \% \\
(88)\end{array}$ & $\begin{array}{c}44.2 \% \\
(87)\end{array}$ & $\begin{array}{c}8.1 \% \\
(16)\end{array}$ & $\begin{array}{l}3.0 \% \\
(6)\end{array}$ & $\begin{array}{l}0 \% \\
(0)\end{array}$ \\
\hline $\begin{array}{l}\text { Fever and blister on the hand, foot, mouth and tongue } \\
\text { are the most common. }\end{array}$ & $\begin{array}{c}50.8 \% \\
(100)\end{array}$ & $\begin{array}{c}41.6 \% \\
(82)\end{array}$ & $\begin{array}{l}5.6 \% \\
(11)\end{array}$ & $\begin{array}{c}2.0 \% \\
(4)\end{array}$ & $\begin{array}{l}0 \% \\
(0)\end{array}$ \\
\hline $\begin{array}{l}\text { Children toys are intermediate channels from } \\
\text { transmitting of HFMD. }\end{array}$ & $\begin{array}{l}44.7 \% \\
(88)\end{array}$ & $\begin{array}{l}45.2 \% \\
(89)\end{array}$ & $\begin{array}{l}7.1 \% \\
(16)\end{array}$ & $\begin{array}{c}3.0 \% \\
(6)\end{array}$ & $\begin{array}{l}0 \% \\
(0)\end{array}$ \\
\hline
\end{tabular}

\section{HFMD knowledge and demographic factors}

Two demographic variables were associated with caretaker knowledge. In this study, knowledge about HFMD was found to be associated with age using the Pearson Correlation product moment correlation coefficient. However, the correlation between the two variables showed that medium levels of knowledge control were associated with the age of caretakers, (r 0.34, $\mathrm{n}=197, \mathrm{p}<0.005)$. The researchers managed to get results with a very small correlation between knowledge and the length of service between both variables, ( $\mathrm{r} 0.22, \mathrm{n}=197, \mathrm{p}<0.005)$, with small levels of knowledge control being associated with the length service of care takers.

At the same time, the researchers explored the relationship between knowledge and the caretakers' marital status in terms of Pearson correlation. The analysis were executed to ensure no violation of assumptions of normality, linearity and homoscedasticity. There was no correlation between both variables ( $\mathrm{r}$ 0.34, $\mathrm{n}=197, \mathrm{p}>0.005)$ of knowledge and marital status of the caretakers. Finally, the relationship between knowledge score and level of education among caretakers as investigated using Pearson Correlation was measured as well. There was no correlation between knowledge and education level of the caretakers ( $\mathrm{r} 0.48, \mathrm{n}=197$, $\mathrm{p}>0.005)$.

Table 3: Association between knowledge and demographic factors

\begin{tabular}{ccc}
\hline Variables & P-value & Pearson Correlatin \\
\hline Age & $\mathrm{P}<0.005$ & $0.37^{*}$ \\
\hline Marital status & $\mathrm{P}>0.005$ & 0.34 \\
\hline Level of education & $\mathrm{P}>0.005$ & 0.48 \\
\hline Length of service & $\mathrm{P}<0.005$ & $0.22^{*}$ \\
\hline * Statistically significant correlation at $\mathrm{p}$-value $<0.0005$
\end{tabular}

| Volume:4 | Issue: 11 | November| 2019 Journal DOI: https://doi.org/10.36713/epra2016 |www.eprajournals.com |77| 


\section{HFMD source of information}

Some responses provided in the additional column mentioned that they caught sources of knowledge from the kindergarten where they work, media such as radio, and workshops and courses they attended outside their work premises. As the researcher detailed the answer given $82(41.6 \%)$ respondents have selected only one option from the given answer. Two answers were selected by 34 participants $(17.3 \%)$. The remainder at $81(41.1 \%)$ responded with three and more options for receiving HFMD information. Electronic media such as television and radio were the most selected mediums by the caretakers. This was followed by social media such as WhatsApp and Facebook. Several participants mentioned that they got the knowledge about the HFMD when they attended courses conducted by their institution or by visiting a hospital. The combination of social media and electronic media dominated the information getting by them. Those below 40 years old preferred gaining information from the internet with a combination of other methods. However, those 41 to 59 years old favoured mediums such as television and the internet for getting HFMD knowledge.

\section{DISCUSSION}

This study found that caretakers have inadequate of overall knowledge equivalent to moderate and tendency to low about HFMD matters. The findings of the research in terms of consistency corroborate work by researchers such as Charoenchokpanit and Pumpaibool (2013) and Qudsiah et al. (2017) Almost half of caregivers for children below five years in a study conducted in Bangkok lacked knowledge about HFMD Charoenchokpanit and Pumpaibool (2013). In addition, a study by Qudsiah et al. (2017) among mothers of preschool children in Klang, Malaysia demonstrated the same situation for inadequate knowledge about HFMD. Another research organized among visitors to a hospital in Malaysia has shown that almost half of the participants did not have general knowledge about HFMD and some had no clue about the illness as well Othman et al. (2012).

In this outcome, only two demographic factors, age and length of service, were associated with knowledge. In this outcome, the researchers have uncovered that there was a medium relationship between knowledge and age of the caretakers. There are combination of result that support and contradict with the findings Charoenchokpanit and Pumpaibool (2013). It is found that there is an association between caregivers' age and knowledge about HFMD. Fenwick et al. (2013) governed the same result too when they showed the existence of relationship among elderly with diabetic knowledge.
However, several studies about breastfeeding Afrose et al. (2012) and diabetes Herald et al. (2017) have disclosed that no significant relationship between age and knowledge in their studies.

It is reasonable that staffs with several years of experience are more knowledgeable than the novice. As Woodruffe (1999) explained that those with experience are more knowledgeable workers. The researchers have found that knowledgeable caretakers who have work more in the kindergarten with the children. Quite a lot of researches support this finding. For instance, nurses who have served for more than five years are more conversant as compared with those junior from them Teshager et al. (2015). A similar situation can be seen with health care professionals in hospitals those with more working experience tend to share their wisdom with other staff Asemahag (2014).

In this study, education level and marital status have shown no relationship with knowledge. Quite a few studies obtained the same result as well. For example, Al Maskari (2013) found that marital status does not influence diabetes knowledge among their respondents. In addition to that, dengue knowledge among selected Malaysian has no association with several demographic variables, including marital status Al-Dubai et al. (2013). Akhtari-Zavare et al. (2014) also found no connection between breast cancer knowledge and marital status. Various other studies have demonstrated that level of education may be significantly associated with knowledge Al Maskari (2013), Liu et al. (2016), Herath et al. (2017). For this present study, sources of information about HFMD are monopolized by electronic media such as television and radio among caretakers. This was followed by social media such as WhatsApp messenger and Facebook. Charoenrokpanit and Pumpaibool (2013) obtained similar results and have confirmed that television is the most preferred in Bangkok among caregivers. However, contradictory results from Othman et al. (2012) showed that respondents favoured newspapers $(40 \%)$ and television (23\%). If we refer to the current trend, the main source of information for health issues Bianco et al. (2013), Antheunis (2013), Ventola (2014), Tayebi (2019) is obviously social media.

\section{CONCLUSION}

In conclusion, a majority of caretakers had a lack of HFMD knowledge. Educational background did not reflect the knowledge among caretakers, but age and length of services does. Persistent education of caretakers by the preschool management would go a long way towards increasing knowledge of HFMD disease was needed. Consistent information about HFMD in electronic and social media is required. It 
is important to determine if certain classes of health information sources are more effective than others.

\section{REFERENCES}

1. World Health Organization. (2016). Hand, Foot, and Mouth Disease. Information Sheet. Available from http:// www. wpro. who. int/ emerging _diseases / hfmd information. sheet/en/

2. World Health Organization. (2011). A guide to Clinical Management and Public Health response for Hand, Foot and Mouth Disease (HFMD). Available from

http//www.wpro.who.int/publications/docs/Guida ncefortheclinicalmanagementofhfmd .pdf.

3. Othman, N., Wi,W., Che Lamin, R., Othman, C.N., Md Nor Nurul Huda., Mazlan, N. (2012). Knowledge Attitude and Practices Regarding Hand, Food, and Mouth Disease (HFMD) of Visitors in Hospital Tengku Ampuan Afzan, Pahang.

4. Charoenchokpanit, R., Pumpaibool, T.(2013). Knowledge Attitude and Preventive Behaviors towards Hand Foot Mouth Disease among Caregivers of Children Underfive years old in Bangkok, Thailand. J Health Res.;27(5):281-286.

5. Qudsiah, S., Salmiah, M. S., Nor Afiah, M. Z. (2017). Predictors of Preventive Practices towards HFMD among Mothers of Preschool Children in Klang District. Malaysian Journal of Medicine and Health Sciences.;13(3):21-32.

6. Fenwick, E. K., Xie, J., Rees, G., Robert P. (2013). Factors Associated with Knowledge of Diabetes in Patients with Type 2 Diabetes Using the Diabetes Knowledge Test Validated with Rasch Analysis.

7. Afrose, L., Banu, B.. Ahmed, R,. Khanom, K,. (2012). Factors Associated with Knowledge about Breastfeeding among Female Garment Workers in Dhaka City. Department of Health Education and Health Promotion, Institute of Health Science (BIHS), Dhaka, Bangladesh.;1(3):249-255.

8. Herath, N. P. Weerasinghe, H., Dias, T. P., Weerarathna. (2017). Knowledge, Attitude and Practice Related to Diabetes Mellitus among the General Public in Galle District in Southern Sri Lanka: A Pilot Study. BMC Public Health.;17(535).

9. Woodruffe, C. (1999).Winning the Talent War: Winning the Talent War: A Strategic Approach to Attracting, Developing and Retaining the Best People, Chichester, UK: John Wiley \& Sons.

10. Teshager, F. A., Engeda, E. H., and Worku, W. Z. (2013). Knowledge, Practice, and Associated Factors towards Prevention of Surgical Site Infection among Nurses Working in Amhara Regional State Referral Hospitals, Northwest Ethiopia. Surgery Research and Practice. Available from http://dx.doi.org/10.1155/2015/736175

11. Asemahagn, M. A. (2014). Knowledge and Experience Sharing Practices Among Health Professionals in Hospitals Under the Addis Ababa Health Bureau, Ethiopia. BMC Health Services Research.; 14(431).

12. Al-Maskari, F., El-Sadig, M., Juma M., Al-Kaabi., Afandi, B., Nicolas, N., Karin, B. (2013). Knowledge, Attitude and Practices of Diabetic Patients in the United Arab Emirates. Available from

https://doi.org/10.1371/journal.pone.0052857

13. Al-Dubai, S. A. R., Ganasegeran, K., Alwan, M. R., Alshagga, M. A., Saif-Ali, R. (2013). Factors Affecting Dengue Fever Knowledge, Attitudes and Practices among Selected Urban, Semi-Urban and Rural Communities in Malaysia.;44(1):37-49.

14. Akhtari-Zavare M., Ghanbari, A., Baghestan., Latiffah, A., Matinnia, N., Hoseini, M. (2014). Knowledge of Breast Cancer and Breast SelfExamination Practice Among Iranian Women in Hamedan, Iran. Asian Pacific Journal of Cancer Prevention:; 15(16): 6531-6534.

15. Liu, Y., Li J., Zheng, Q., Charles, M., Brian, J. H., Li, X., Hao, Y. (2016). Knowledge, Attitudes, and Perceptions of Autism Spectrum Disorder in a Stratified Sampling of Preschool Teachers in China. BMC Psychiatry.; 16(142).

16. Bianco, A., Zucco, R., Giuseppe, C., Nobile, A., Pileggi, C., Pavia, M. (2013). Parents Seeking Health-Related Information on the Internet: CrossSectional Study. Journal of Medical Internet Research.;15(9).

17. Antheunis, A., Marjolijn, L., Kiek, Tates A., Theodoor, E., Nieboer, B. (2013). Patients and Health Professionals use of Social Media in Health Care: Motives, Barriers and Expectations. Education and Counseling.;9(2): 426-431.

18. Ventola, C. L. (2014). Social Media and Health Care Professionals: Benefits, Risks, and Best Practices. P\&TT.;39(7):491-499.

19. Tayebi, S., Manesh, S., Khalili, M., Sadi-Nezhad, S. (2019). The role of Information Systems in Communication Through Social Media. International Journal of Data and Network Science.;3(3):245-268.

| Volume:4| Issue: 11 | November| 2019 Journal DOI: https://doi.org/10.36713/epra2016 |www.eprajournals.com |79 | 